\title{
Ability of Four Emergent Macrophytes to Remediate Permethrin in Mesocosm Experiments
}

\author{
M. T. Moore $\cdot$ R. Kröger $\cdot$ C. M. Cooper $\cdot$ \\ S. Smith Jr.
}

Received: 12 January 2009/Accepted: 28 April 2009/Published online: 21 May 2009

(C) US Government 2009

\begin{abstract}
Increased focus is being placed on the ability of native vegetation to mitigate potential harmful effects of agricultural runoff, especially pyrethroid insecticides. Replicate $379 \mathrm{~L}$ Rubbermaid tubs $(1.25 \mathrm{~m} \mathrm{[1] \times 0.6 \textrm {m }}$ $[\mathrm{w}] \times 0.8 \mathrm{~m}[\mathrm{~h}])$ were planted with individual species of cutgrass (Leersia oryzoides), cattails (Typha latifolia), burreed (Sparganium americanum), and powdery alligator-flag (Thalia dealbata), all common wetland macrophytes found in the Mississippi Delta, USA, agricultural region. Permethrin-enriched water (target concentration, $5 \mu \mathrm{g} \mathrm{L}{ }^{-1}$ ) was pumped in at a 4-h hydraulic retention time at one end of the tub and discharged at the far end. Water samples were collected from discharge at 1-h intervals for $12 \mathrm{~h}$ and analyzed for permethrin concentrations. Permethrin removal rates were compared for the four different plant treatments and nonvegetated sediment-water controls. Results indicated that no particular single plant species was more effective at removing permethrin in water relative to unplanted controls. Overall mass reductions (from inflow to outflow) for cis-permethrin ranged from $67 \% \pm 6 \%$ in T. latifolia to $71 \% \pm 2 \%$ in L. oryzoides. The trans-permethrin overall mass reductions ranged from $76 \% \pm 4 \%$ in S. americanum to $82 \% \pm 2 \%$ in the unplanted control. Sediment and plant samples collected at the study conclusion indicated that $77 \%-95 \%$ of measured permethrin mass was associated with sediment for mesocosms planted with $L$. oryzoides, $T$. latifolia, and $T$. dealbata. Conversely,
\end{abstract}

M. T. Moore $(\bowtie) \cdot$ C. M. Cooper · S. Smith Jr. USDA-ARS National Sedimentation Laboratory, P.O. Box 1157, Oxford, MS 38655, USA

e-mail: matt.moore@ars.usda.gov

R. Kröger

Department of Wildlife and Fisheries, Mississippi State

University, P.O. Box 9690, Mississippi State, MS 39762, USA mesocosms planted with $S$. americanum had $83 \%$ of measured mass associated with the plant material. Specific plant-pesticide retention studies can lead to improved planning for best management practices and remediation techniques such as constructed wetlands and vegetated agricultural drainage ditches.

Contamination of water bodies worldwide by non-pointsource pollution, specifically pesticides, has led to increasing attention focused on agricultural runoff. Pesticide pollution is one of the most significant threats to the integrity of the world's surface waters. In the United States, slightly more than 1300 (2\%) of reported impairments to water bodies are attributed to pesticides (USEPA 2008). Studies from across the world have examined the presence of pesticides in surface waters (House et al. 1991; Kreuger 1998; Bar-Ilan et al. 2000; Schulz et al. 2001; Tanabe et al. 2001).

Permethrin [3-phenoxybenzyl-(1RS)-cis,trans-3-(2,2-dichlorovinyl)-2,2-dimethylcyclopropanecarboxylate] is a pyrethroid insecticide sold under trade names such as Ambush and Pounce (Table 1). Its first registered use in the United States was for cotton (Gossypium hirsutum) in 1979; however, in 1994 producers requested voluntary cancellation for cotton use (USEPA 2006). Current permethrin registrations include use in or on a variety of food/ feed crops, livestock, structures, pets, residential dwellings, and clothing (USEPA 2006). Annually it is estimated that $900,000 \mathrm{~kg}$ of permethrin is applied to agricultural, residential, and public health uses, with only $30 \%$ actually being applied in agricultural settings (USEPA 2006). More than $630,000 \mathrm{~kg}$ is annually applied in nonagricultural 
Table 1 Selected physical and chemical properties of permethrin

Chemical structure

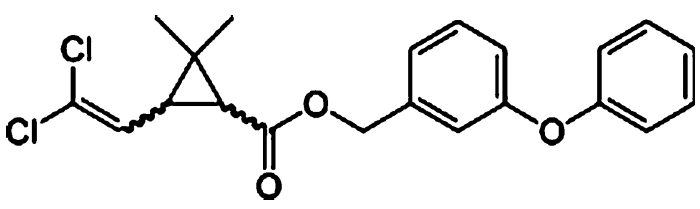

Molecular weight

Water solubility $\left(\mathrm{mg} / \mathrm{L} \text { at } 25^{\circ} \mathrm{C}\right)^{\mathrm{a}}$

$K_{\text {ow }}^{\mathrm{b}}$

$K_{\mathrm{oc}}^{\mathrm{b}}$

Hydrolysis $\left(t_{1 / 2}\right)$ (days at $\left.20^{\circ} \mathrm{C}\right)^{\mathrm{b}}$

$\mathrm{pH} 5$

$\mathrm{pH} 7$

$\mathrm{pH} 9$

Aqueous photolysis $\left(t_{1 / 2}\right)\left(\text { days at } 25^{\circ} \mathrm{C}\right)^{\mathrm{a}} \mathrm{pH} 5$
391.28

0.0055

$1.26 \times 10^{6}$

$16,400-550,000$

Stable

Stable

242

$51-71$

${ }^{\mathrm{a}}$ From Imgrund (2003)

b Laskowski (2002)

settings, with $41 \%$ of those applications being made by homeowners on residential areas (USEPA 2006). In tropical locations, permethrin is an effective tool for impregnation on clothing and netting to combat mosquito-borne illnesses. Even though the majority of permethrin use is nonagricultural, several studies across the United States, Sweden, and the United Kingdom have reported permethrin's presence in surface water bodies receiving runoff (Kreuger and Brink 1988; Cooper 1991; House et al. 1991; Kirby-Smith et al. 1992; Kreuger et al. 1999; Daniels et al. 2000).

Using vegetation to transfer or transform pollutants is becoming a more popular practice, especially in areas where the potential exists for pesticide pollution. Susarla et al. (2002) noted plants' abilities to modify certain conditions of their environment as well as their unique enzymatic systems as two potential reasons for the success of phytoremediation. Constructed wetlands, which utilize manipulations of hydroperiod, hydric soils, and aquatic vegetation, have been shown to be effective in removing pesticides from runoff water (Wolverton and Harrison 1973; Gilliam 1994; Moore et al. 2000, 2001a, 2002, 2006). In addition to constructed wetland research, recent studies have examined the use of vegetated agricultural drainage ditches for their potential in pesticide mitigation. Studies by Moore et al. (2001b), Cooper et al. (2004), and Bennett et al. (2005) have indicated the value of vegetated agricultural drainage ditches in the Mississippi Delta for mitigation of pyrethroid-associated storm runoff. These studies, in addition to the constructed wetland studies, utilized plant communities which were often mixtures of several emergent species. The present study involved the use of mesocosms with monocultures of four common emergent ditch macrophytes to determine which, if any, of the four species, is most effective at removing permethrin concentrations from pesticide-enriched flowing water.

\section{Materials and Methods}

Over the summer of 2006, individual mesocosms (1.25 m [l] $\times 0.6 \mathrm{~m} \mathrm{[w]} \times 0.8 \mathrm{~m} \mathrm{[h])}$ were planted with four different aquatic plant species at the U.S. Department of Agriculture (USDA)-Agricultural Research Service (ARS), National Sedimentation Laboratory (NSL), Oxford, Mississippi. Plant stocks were collected from the USDA Natural Resource Conservation Service (NRCS), Plant Materials Center, Coffeeville, Mississippi, and from the University of Mississippi Field Station (UMFS), Abbeville. In the summer of 2007, these plant species were compared against a nonvegetated control to determine the influence of species-specific vegetation on permethrin mitigation. Individual plant species selected were cutgrass (Leersia oryzoides L.), cattail (Typha latifolia L.), bur-reed (Sparganium americanum Nutt.), and powdery alligator-flag (Thalia dealbata Fraser ex Roscoe). All four species are common species in surface vegetated agricultural ditches in the Mississippi Delta, USA. Plant species were classified as obligate wetland plants for the southeast region. There were three mesocosm replicates per species and nonvegetated control (total $N=15$ ), and all mesocosms were randomly arranged.

Target permethrin runoff concentrations were $0.1 \%$ of typical insecticide applications applied to an 80-acre 
(32-ha) agricultural field. Pesticide-enriched Oxford, Mississippi, municipal well water (target permethrin concentration, $5 \mu \mathrm{g} \mathrm{L}^{-1}$ ) was prepared in reservoirs and pumped into individual mesocosms at the water surface. Water flowed through each mesocosm and exited at the surface through a discharge hose at the opposite end of the mesocosm (Fig. 1). Each mesocosm was hydrologically regulated for a 4-h residence time. The 4-h targeted permethrin "runoff" dose was delivered using Fluid Metering Inc. (FMI) lab pumps, models QD-1 (flow range, 0-552 mL/ min) and QD-2 (flow range, $0-1242 \mathrm{~mL} \mathrm{~min}^{-1}$ ) at a calculated rate per mesocosm. After $4 \mathrm{~h}$, new delivery hosing provided "clean" (unamended) municipal well-water runoff for an additional $8 \mathrm{~h}$. Water samples were collected pre-exposure to identify background levels and, subsequently, sampled every hour for $12 \mathrm{~h}$ from the outflow of each mesocosm. Bulk plant and sediment samples were taken 1 week after the experiment to determine pesticide assimilation. Excess water was drained into large $(38,000-\mathrm{L})$ open-air sumps, heavily diluted, and stored for 2 weeks to further photolytic degradation.

Water samples were collected in 1-L amber glass jars and immediately brought into the laboratory and fixed with $500 \mathrm{mg} \mathrm{KCl}$ and $25 \mathrm{~mL}$ distilled ethyl acetate. Samples were prepared for gas chromatography using standard techniques for pesticide analysis (Bennett et al. 2000; Smith and Cooper 2004; Smith et al. 2006). Samples were extracted using sonication and transferred into a $250-\mathrm{mL}$ separatory funnel (Bennett et al. 2000). After separation, the organic layer was transferred through sodium sulfate and concentrated under UHP nitrogen to a $2-\mathrm{mL}$ volume. Centrifugation and further concentration produced the final $1-\mathrm{mL}$ volume required for gas chromatography. At the conclusion of the experiment, triplicate plant and soil

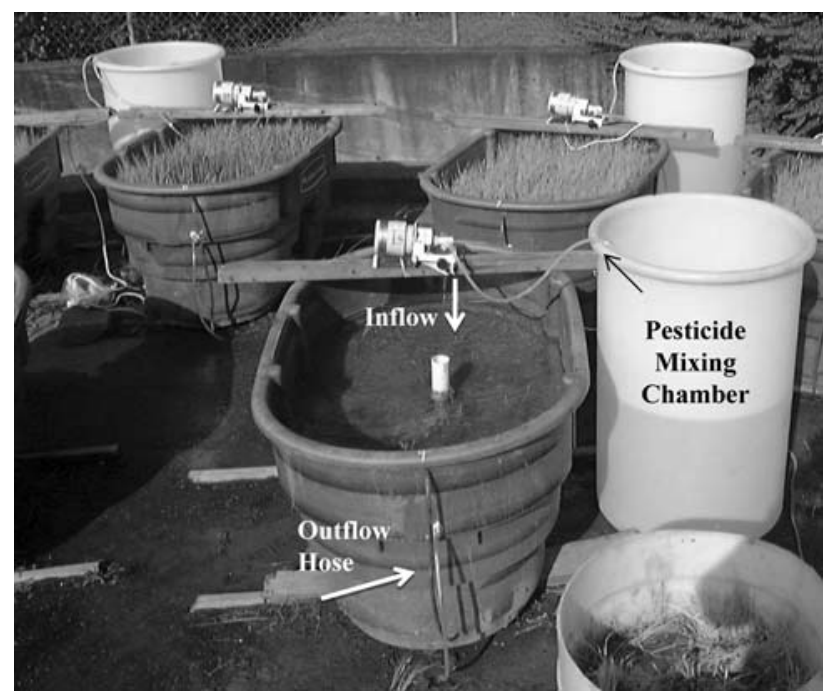

Fig. 1 Experimental mesocosm demonstration with input and output samples (10 g dry weight) were collected, air-died, ground using a Wiley-mill (2-mm mesh diameter), and prepared for analysis following the procedure outlined by Bennett et al. (2000).

Water, soil, and plant analytes were analyzed with a model Agilent 7890 gas chromatograph, equipped with dual Agilent ALS autoinjectors, dual capillary columns, and an Agilent Chemstation (Smith and Cooper 2004; Smith et al. 2006). Two isomers of permethrin (cis- and trans-) were targeted for analysis. The gas chromatograph was equipped with two Agilent micro-electron capture detectors. The main analytical column was a HP 1MS capillary column, with UHP helium carrier gas. The microelectron capture detector had an analytical temperature of $325^{\circ} \mathrm{C}$ with a constant makeup gas of UHP nitrogen. Under these conditions, retention times for cis- and trans-permethrin were 15.4 and $15.9 \mathrm{~min}$, respectively, over a single run of $61 \mathrm{~min}$.

Mitigation capacity was measured as the concentration or load of permethrin (cis- or trans-) retained during the course of the 12-h experiment. Load was determined by multiplying the pesticide concentration by the volume of water moving through the system. Respective individual reduction capacities were normalized by the natural logarithm and were compared with a one-way ANOVA and post hoc Tukey honestly significantly different tests, $\alpha=0.05$.

\section{Results}

Inflow and outflow concentrations for cis- and trans-permethrin are presented in Table 2. Overall mass retention for cis-permethrin following the 12-h experiment ranged from $67 \% \pm 6 \%$ in . latifolia to $71 \% \pm 2 \%$ in L. oryzoides (Table 3). Slightly more trans-permethrin mass was retained at the end of the 12-h experiment, ranging from $76 \% \pm 4 \%$ in $S$. americanum to $82 \% \pm 2 \%$ in the unvegetated control (Table 3). Additionally, all plant species retained trans-permethrin more efficiently than cis-permethrin ( $p \leq 0.0001)$ (Figs. 2 and 3). There were no observed significant statistical differences in permethrin mitigation efficiencies of any of the four plant species. Likewise, no statistically significant difference in mitigation efficiency was noted between nonvegetated controls and any of the four plant species. Bulk sediment samples collected at the conclusion of the experiment indicated similar cis- and trans-permethrin masses in all planted and control mesocosms. Additionally, cis-permethrin masses were generally three times greater than trans-permethrin masses (Table 4). Plant species collected at the conclusion of the experiment revealed different mass accumulations in various species. Comparing the plant species to each other, 
Table 2 Mean inflow and outflow permethrin $(\mathrm{P})$ concentrations $(\mu \mathrm{g} / \mathrm{L} \pm \mathrm{SE})$ from mesocosms

\begin{tabular}{lrrrrr}
\hline & \multicolumn{1}{c}{ Control } & \multicolumn{1}{c}{ Leersia } & \multicolumn{1}{c}{ Typha } & \multicolumn{1}{c}{ Sparganium } \\
\hline cis-P Inflow & $8.09 \pm 0.560$ & $4.54 \pm 2.23$ & $7.03 \pm 0.297$ & $6.44 \pm 0.808$ & $7.13 \pm 0.776$ \\
Outflow 4 h & $1.23 \pm 0.210$ & $1.30 \pm 0.270$ & $1.12 \pm 0.190$ & $1.14 \pm 0.188$ & $1.44 \pm 0.256$ \\
$12 \mathrm{~h}$ & $0.762 \pm 0.147$ & $0.621 \pm 0.148$ & $0.674 \pm 0.130$ & $0.625 \pm 0.113$ & $0.689 \pm 0.136$ \\
trans-P Inflow & $6.58 \pm 0.430$ & $3.69 \pm 1.83$ & $5.75 \pm 0.274$ & $5.27 \pm 0.671$ & $5.83 \pm 0.660$ \\
Outflow 4 h & $0.588 \pm 0.117$ & $0.777 \pm 0.183$ & $0.722 \pm 0.151$ & $0.739 \pm 0.136$ & $0.743 \pm 0.119$ \\
$12 \mathrm{~h}$ & $0.349 \pm 0.059$ & $0.347 \pm 0.096$ & $0.355 \pm 0.077$ & $0.364 \pm 0.073$ & $0.355 \pm 0.067$ \\
\hline
\end{tabular}

Table 3 Overall mass retentions (\% \pm SE) of permethrin-amended mesocosms

\begin{tabular}{lll}
\hline Vegetation & cis-Permethrin & trans-Permethrin \\
\hline Leersia oryzoides & $71 \pm 2$ & $81 \pm 1$ \\
Typha latifolia & $67 \pm 6$ & $78 \pm 2$ \\
Sparganium americanum & $67 \pm 8$ & $76 \pm 4$ \\
Thalia dealbata & $68 \pm 3$ & $79 \pm 4$ \\
Nonvegetated control & $69 \pm 7$ & $82 \pm 2$ \\
\hline
\end{tabular}

statistically significant differences $(\alpha=0.05)$ were noted in cis-permethrin plant masses of $T$. latifolia and $S$. americanum. Statistically significant differences were also noted between $L$. oryzoides and $T$. dealbata cis-permethrin plant masses. All other relationships between cispermethrin masses of the plant species did not yield any statistically significant differences at the $\alpha=0.05$ level. No statistically significant differences were noted among trans-permethrin plant masses of any of the four plant species.

\section{Discussion}

Permethrin, like other pesticides and agricultural pollutants, can end up in aquatic receiving systems in a variety of ways; however, it is most often as a result of runoff generated either from an irrigation release or from a storm event (Schulz 2004). Willis et al. $(1986,1994)$ conducted studies on permethrin washoff from cotton plants as a result of rainfall. Their results demonstrated that rainfall amount was more of a contributing factor to permethrin washoff than was rainfall intensity (Willis et al. 1986). When rainfall occurred $2 \mathrm{~h}$ after permethrin application, $58 \%$ of the cotton plant's permethrin load was washed off (Willis et al. 1994). This permethrin load would then be transported to an aquatic receiving system where it could potentially impact aquatic flora and fauna.

While permethrin in an aquatic receiving system has been shown to impair nontarget invertebrates, recent studies have probed the question of bioavailability of permethrin associated with dissolved organic material and suspended sediments. Yang et al. (2007) suggested no significance
Fig. 2 Percentage reduction of cis-permethrin by four emergent macrophytes

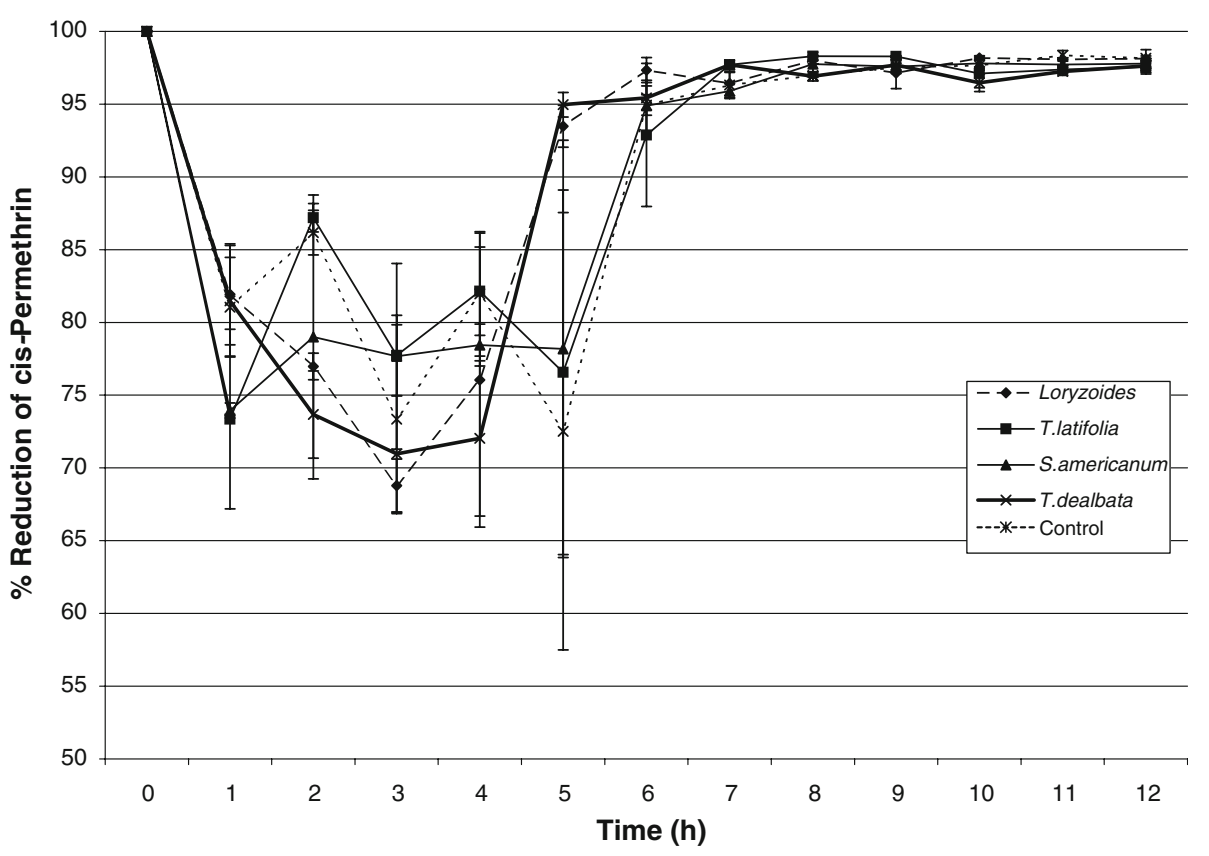


Fig. 3 Percentage reduction of trans-permethrin by four emergent macrophytes

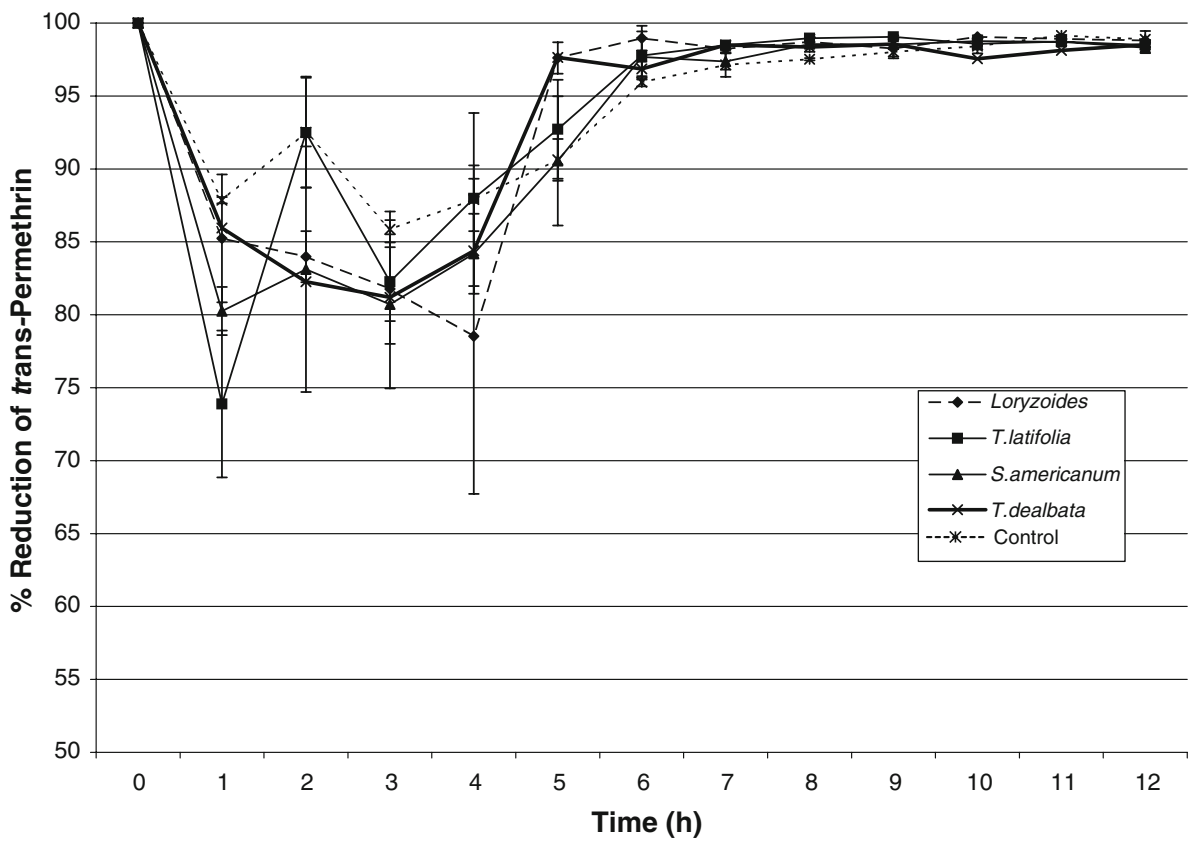

Table 4 The cis- and trans-permethrin $(\mathrm{P})$ masses $(\mu \mathrm{g} \pm \mathrm{SE})$ measured in sediment and plant samples collected at the end of the 12-h experiment

\begin{tabular}{|c|c|c|c|c|}
\hline \multirow[t]{2}{*}{ Vegetation } & \multicolumn{2}{|l|}{ Sediment } & \multicolumn{2}{|l|}{ Plant } \\
\hline & $c i s-\mathrm{P}$ & trans $-\mathrm{P}$ & cis $-\mathrm{P}$ & trans $-\mathrm{P}$ \\
\hline Leersia oryzoides & $219 \pm 4.75$ & $67.0 \pm 10.6$ & $9.09 \pm 2.08$ & $4.14 \pm 0.690$ \\
\hline Typha latifolia & $249 \pm 53.6$ & $81.4 \pm 29.4$ & $60.4 \pm 40.3$ & $32.4 \pm 17.5$ \\
\hline Sparganium americanum & $200 \pm 4.52$ & $60.8 \pm 5.42$ & $746 \pm 214$ & $398 \pm 140$ \\
\hline Thalia dealbata & $226 \pm 36.2$ & $81.4 \pm 29.4$ & $64.7 \pm 7.05$ & $25 \pm 6.26$ \\
\hline Nonvegetated control & $204 \pm 13.1$ & $61.2 \pm 10.6$ & NA & NA \\
\hline
\end{tabular}

NA, not available

existed when examining the effects of dissolved organic material on permethrin toxicity and bioavailability to D. magna and C. dubia. Studies conducted by Yang et al. (2006) reported decreased uptake of $\left[{ }^{14} \mathrm{C}\right]$ permethrin in D. magna after $24 \mathrm{~h}$, corresponding to increased levels of suspended solids ranging from 0 to $200 \mathrm{mg} \mathrm{L}^{-1}$.

Effects literature has established potential harm to flora and fauna when permethrin makes its way into aquatic receiving systems. Once permethrin, or any contaminant, has made its way into an aquatic system, according to the laws of thermodynamics, that contaminant can only be transformed or transferred. Transformations can occur through breakdown of parent compound into metabolites or other means of degradation. Lutnicka et al. (1999) reported permethrin half-lives ranging from 1.1 to 3.6 days in $15-19^{\circ} \mathrm{C}$ water. When cis- and trans-permethrin were applied to the surface of a New Zealand stream, 50\% and $60 \%$ of the applied respective masses were lost from water within $545 \mathrm{~m}$ of the study reach (Wilcock et al. 1994).
Dissipation of permethrin in limnocorrals reportedly followed first-order kinetics within the first 8-12 days, with rapid sorption to sediments (Solomon et al. 1985). Results of the current study demonstrated measurable mass associated with the sediment phase; however, no significant differences were noted in sediment masses between vegetated and unvegetated mesocosms. Permethrin transformation by microbes may also occur in aqueous environments. Aeromonas sobria, Erwinia carotovora, and Yersinia frederiksenii were each capable of degrading isomers of permethrin, in addition to reducing permethrin's half-life approximately 10 times (Lee et al. 2004).

Research reported in this study focused on using vegetation to transfer permethrin out of associated runoff water. Several factors influence the ability of vegetation to transfer pesticides from water, including the physicochemical properties of the particular pesticide, as well as the biochemical characteristics of the plant (Garcinuno et al. 2006). The current results, although using different 
plant species, support those of Rawn et al. (1982), who reported that permethrin $\left(15 \mu \mathrm{g} \mathrm{L}{ }^{-1}\right.$ treatment) was readily sorbed by duckweed, while sediment served as a major sink for the pesticide. Additionally, Moore et al. (2008) reported that approximately $50 \%$ of both cis- and trans-permethrin masses were associated with the sediment phase, while $33 \%$ of both isomers were associated with drainage ditch plant material. Garcinuno et al. (2006) determined that pesticide concentrations were higher in root material than in shoot material of Lupinus angustifolius, and no accumulation was noted in plant cotyledons. This is important to note, since many critics of phytoremediation are concerned with further pesticide transport through the food chain or continued plant development. Additionally, Garcinuno et al. (2006) found that $55 \%$ of recovered permethrin mass was either degraded or bound irreversibly to L. angustifolius material. In a Canadian headwater stream study, Sundaram (1991) reported that stream detritus generally had two times the permethrin concentration found in aquatic plants in the same system. The same study also determined that permethrin residues in pond sediment were two times greater than those in pond detritus, which in turn were over 20 times greater than residues found in water. The potential for plant uptake depends on many factors, including pesticide chemistry and plant lipid content. Permethrin is highly lipophilic, and in the presence of vegetation with high lipid contents, the insecticide can be expected to sorb with vegetative material. While the lipid content of the vegetation used in this study was not evaluated, it is evident that further investigation into this question is needed to adequately answer pesticide-plant sorption scenarios. In the current study, a potential cause for seeing no significant difference between vegetated and unvegetated mesocosms is the relatively short (4-h) pesticide residence time. Even with a longer ditch residence time (nearly $8 \mathrm{~h}$ ), Moore et al. (2008) found that the mean measured masses of both cis- and trans-permethrin in the water column of an unvegetated ditch were equivalent to permethrin water concentrations found in an equivalent vegetated ditch.

Phytoremediation is a growing field and further research will be vital to unlocking the opportunities of using natural systems to improve the quality of pesticide-associated runoff water. Benefits and impacts of using vegetation to clean non-point-source runoff extend beyond North America, especially in developing countries, where expensive remediation techniques are often impossible. Although none of the four macrophytes used in this study were deemed to be more efficient at remediating permethrin than nonvegetated controls, recovered permethrin mass in plant samples following the 12-h experiment indicate vegetation's potential role in cleaning water impacted by pesticide runoff. Further studies are examining increased hydraulic retention times and mixed plant communities for more effective permethrin remediation.

Acknowledgments The authors thank L. Brooks, R. L. Lee, C. Helms, R. Menon, and B. McNeely for sample collection and analysis assistance. Thanks also go to P. Rodrigue and the USDA-NRCS Plant Materials Center in Coffeeville, Mississippi.

\section{References}

Bar-Ilan I, Shmerkin S, Mingelgrin U, Levanon D (2000) Survey of pesticide distribution in upper Jordan basin. Water Air Soil Pollut 119:139-156. doi:10.1023/A:1005138411271

Bennett ER, Moore MT, Cooper CM, Smith S Jr (2000) Method for simultaneous extraction and analysis of two current use pesticides, atrazine and lambda-cyhalothrin, in sediment and aquatic plants. Bull Environ Contamin Toxicol 64:825-833. doi: 10.1007/s001280000077

Bennett ER, Moore MT, Cooper CM, Smith S Jr, Shields FD Jr, Drouillard KG, Schulz R (2005) Vegetated agricultural drainage ditches for the mitigation of pyrethroid-associated runoff. Environ Toxicol Chem 24(9):2121-2127. doi:10.1897/04357R.1

Cooper CM (1991) Persistent organochlorine and current use insecticide concentrations in major watershed components of Moon Lake, Mississippi, USA. Arch Hydrobiol 121:103-113

Cooper CM, Moore MT, Bennett ER, Smith S Jr, Farris JL, Milam CD, Shields FD Jr (2004) Innovative uses of vegetated drainage ditches for reducing agricultural runoff. Water Sci Technol 49(3):117-123

Daniels WM, House WA, Rae JE, Parker A (2000) The distribution of micro-organic contaminants in river bed-sediment cores. Sci Total Environ 253:81-92. doi:10.1016/S0048-9697(00)00379-X

Garcinuno RM, Fernandez-Hernando P, Camara C (2006) Removal of carbaryl, linuron, and permethrin by Lupinus angustifolius under hydroponic conditions. J Agric Food Chem 54:5034-5039. doi: 10.1021/jf060850j

Gilliam JW (1994) Riparian wetlands and water quality. J Environ Qual 23:896-900

House WA, Farr IS, Orr DR, Ou Z (1991) The occurrence of synthetic pyrethroid and selected organochlorine pesticides in river sediments. Br Crop Protect Council Monogr 47:183-192

Imgrund H (2003) Environmental fate of permethrin. Available at: http://www.cdpr.ca.gov/docs/emon/pubs/fatememo/permethrin. pdf. Accessed January 9, 2009

Kirby-Smith WW, Eisenreich SJ, Howe JT, Luettich RA Jr (1992) The effects in estuaries of pesticide runoff from adjacent farm lands. Final project report. U.S. Environmental Protection Agency, Gulf Breeze, FL

Kreuger J (1998) Pesticides in stream water within an agricultural catchment in southern Sweden, 1990-1996. Sci Total Environ 216:227-251

Kreuger JK, Brink N (1988) Losses of pesticides from agriculture. In: Pesticides: food and environmental implications. International Atomic Energy Agency, Vienna, Austria, pp 101-112

Kreuger J, Peterson M, Lundgren E (1999) Agricultural inputs of pesticide residues to stream and pond sediments in a small catchment in southern Sweden. Bull Environ Contam Toxicol 62:55-62. doi:10.1007/s001289900841

Laskowski DA (2002) Physical and chemical properties of pyrethroids. Rev Environ Contam Toxicol 174:49-170

Lee S, Gan J, Kim J-S, Kabashima JN, Crowley DE (2004) Microbial transformation of pyrethroid insecticides in aqueous and 
sediment phases. Environ Toxicol Chem 23(1):1-6. doi: 10.1897/03-114

Lutnicka H, Bogacka T, Wolska L (1999) Degradation of pyrethroids in an aquatic ecosystem model. Water Res 33(16):3441-3446. doi:10.1016/S0043-1354(99)00054-8

Moore MT, Rodgers JH Jr, Cooper CM, Smith S Jr (2000) Constructed wetlands for mitigation of atrazine-associated agricultural runoff. Environ Pollut 110:393-399. doi:10.1016/ S0269-7491(00)00034-8

Moore MT, Bennett ER, Cooper CM, Smith S Jr, Shields FD Jr, Milam CD, Farris JL (2001a) Transport and fate of atrazine and lambda-cyhalothrin in an agricultural drainage ditch in the Mississippi Delta, USA. Agr Ecosyst Environ 87:309-314. doi: 10.1016/S0167-8809(01)00148-7

Moore MT, Rodgers JH Jr, Cooper CM, Smith S Jr (2001b) Mitigation of metolachlor-associated agricultural runoff using constructed wetlands. Agr Ecosyst Environ 84:169-176. doi: 10.1016/S0167-8809(00)00205-X

Moore MT, Schulz R, Cooper CM, Smith S Jr, Rodgers JH Jr (2002) Mitigation of chlorpyrifos runoff using constructed wetlands. Chemosphere 46:827-835. doi:10.1016/S0045-6535(01)00189-8

Moore MT, Bennett ER, Cooper CM, Smith S Jr, Farris JL, Drouillard KG, Schulz R (2006) Influence of vegetation in mitigation of methyl parathion runoff. Environ Pollut 142(2):288-294. doi: 10.1016/j.envpol.2005.10.009

Moore MT, Denton DL, Cooper CM, Wrysinski J, Miller JL, Reece K, Crane D, Robins P (2008) Mitigation assessment of vegetated drainage ditches for collecting irrigation runoff in California. J Environ Qual 37:486-493. doi:10.2134/jeq2007.0172

Rawn GP, Webster GRB, Muir DCG (1982) Fate of permethrin in model outdoor ponds. J Environ Sci Health B 17(5):463-486. doi:10.1080/03601238209372335

Schulz R (2004) Field studies on exposure, effects, and risk mitigation of aquatic nonpoint-source insecticide pollution: A review. J Environ Qual 33:419-448

Schulz R, Peall SKC, Dabrowski JM, Reinecke AJ (2001) Spray deposition of two insecticides into surface waters in a South African orchard area. J Environ Qual 30:814-822

Solomon KR, Yoo JY, Lean D, Kaushik NK, Day KE (1985) Dissipation of permethrin in limnocorrals. Can J Fish Aqua Sci 42(1):70-76. doi:10.1139/f85-009

Smith S Jr, Cooper CM (2004) Pesticides in shallow groundwater and lake water in the Mississippi Delta MSEA. In: Nett M, Locke MA, Pennington D (eds), Water quality assessments in the
Mississippi delta, regional solutions, national scope. ACS symposium series 877. American Chemical Society, Oxford University Press, Chicago, IL, pp 91-103

Smith S Jr, Cooper CM, Lizotte RE Jr, Shields FD Jr (2006) Storm pesticide concentrations in Little Toposhaw Creek, USA. Int J Ecol Environ Sci 32:173-182

Sundaram KMS (1991) Fate and short-term persistence of permethrin insecticide injected in a northern Ontario (Canada) headwater stream. Pest Sci 31:281-294. doi:10.1002/ps.2780310304

Susarla S, Medina VF, McCutcheon SC (2002) Phytoremediation: an ecological solution to organic chemical contamination. Ecol Engin 18:647-658. doi:10.1016/S0925-8574(02)00026-5

Tanabe A, Mitobe H, Kawata K, Yasuhara A, Shibamoto T (2001) Seasonal and spatial studies on pesticide residues in surface waters of the Shinano River in Japan. J Agr Food Chem 49:3847-3852. doi:10.1021/jf010025x

USEPA (2006) Permethrin facts (Reregistration Eligibility Decision [RED] fact sheet). EPA 738-F-06-012. U.S. Environmental Protection Agency, Office of Pesticide Programs, Washington, DC

USEPA (2008) Available at: http://iaspub.epa.gov/waters/natio nal_rept.control. Accessed February 20, 2008

Wilcock RJ, Northcott GL, Nagels JW (1994) Mass losses and changes in concentration of chlorpyrifos and cis- and transpermethrin applied to the surface of a stream. Bull Environ Contamin Toxicol 53:337-343. doi:10.1007/BF00197223

Willis GH, McDowell LL, Smith S Jr, Southwick LM (1986) Permethrin wash-off from cotton plants by simulated rainfall. J Environ Qual 15(2):116-120

Willis GH, McDowell LL, Smith S Jr, Southwick LM (1994) Permethrin and sulprofos wash-off from cotton plants as a function of time between application and initial rainfall. J Environ Qual 23:96-100

Wolverton BC, Harrison DD (1973) Aquatic plants for removal of mevinphos for the aquatic environment. J Miss Acad Sci 19: $84-88$

Yang WC, Gan J, Hunter W, Spurlock F (2006) Effect of suspended solids on bioavailablity of pyrethroid insecticides. Environ Toxicol Chem 25(6):1585-1591. doi:10.1897/05-448R.1

Yang WC, Hunter W, Spurlock F, Gan J (2007) Bioavailability of permethrin and cyfluthrin in surface waters with low levels of dissolved organic matter. J Environ Qual 36:1678-1685. doi: 10.2134/jeq2007.0164 